\title{
KONSEP MEDIATEK DALAM PERANCANGAN MEDIA CENTER SEBAGAI THIRD PLACE
}

\author{
Achmad Dimas Haristiyanto1), Doddy Yuono ${ }^{2)}$ \\ 1) Program Studi S1 Arsitektur, Fakultas Teknik, Universitas Tarumanagara, dimas.haristiyanto@gmail.com \\ 2) Program Studi S1 Arsitektur, Fakultas Teknik, Universitas Tarumanagara, masdoddyyuono@gmail.com
}

Masuk: 10-01-2020, revisi: 28-01-2020, diterima untuk diterbitkan: 09-05-2020 (doi: 10.24912/stupa.v2i1.6871)

\begin{abstract}
Abstrak
Third place adalah tempat apapun dalam hidup kita selain daripada tempat bekerja atau rumah. Tempat tersebut menjadi bagian dari pengalaman di tempat kerja yang tidak dapat ditawar, dan berperan penting untuk menarik dan menjaga motivasi kerja kreatif yang dibutuhkan untuk bersaing di masa depan. Perpustakaan adalah salah satu bentuk fisik dari Third place, namun perpustakaan yang ada kurang cocok dengan gaya hidup masyarakat kelas kreatif karena memiliki suasana formal, dengan aturan tegas bagi pengunjung serta waktu pelayanan yang singkat. Oleh karena itu penulis menggunakan teori Third place sebagai pendekatan untuk menjawab isu kebutuhan gaya hidup masyarakat kelas kreatif dengan mengacu standar perpustakaan multimedia. Third place menyediakan ruang fisik dengan fleksibilitas waktu pelayanan, suasana santai untuk bertukar informasi, mengolah ide dan pikiran, dan berinteraksi. Metode yang digunakan pada perancangan ini adalah pencarian ide/gagasan untuk menjawab isu kelas kreatif yang kemudian dikembangkan melalui pengumpulan data sebagai bahan kajian dalam perancangan Mediatheque. Metode yang digunakan dalam pengumpulan data dibagi ke dalam dua kategori, yaitu data primer dan data sekunder. Data primer yaitu data yang diperoleh dari lokasi yang menjadi isu, diamati dan dicatat. Sedangkan data sekunder berupa literatur atau referensi tentang bangunan Mediatheque dikumpulkan untuk mendukung proses menyusun program dalam perancangan. Perancangan Mediatek di Cikini, Jakarta Pusat memiliki konsep mengakomodasi kebutuhan masyarakat kelas kreatif untuk memperoleh informasi akurat, kesempatan saling berinteraksi, membangun relasi, dan berbasis multimedia.
\end{abstract}

\section{Kata kunci: mediatek; multimedia; kelas kreatif; third place}

\begin{abstract}
Third place is any place we spend in our lives other than a place to work or home. It is a non-negotiable part of the workplace experience and very important to attract and motivate creative work we need to compete in the future. Library is a physical example of Third place, however, the existing library is not suitable for the lifestyle of creative class people because it has formal environment, strict regulation, and short opening time. Therefore, this study used the Third place theory as an approach to address issues of the lifestyle needs of creative class communities by referring to the standards of multimedia libraries. Third place provides flexibility in service, relaxed environment for exchanging information, develop ideas and creative thinking, and social interaction. The method used in data collection is divided into two categories, namely primary data and secondary data. Primary data is data obtained from the location of the issue, observed and recorded. While secondary data in the form of literature or references about the Mediatheque building are collected to support the process of compiling the program in the design. The design of Mediatek in Cikini, Central Jakarta has the concept of accommodating the need of creative class community for accurate information, opportunities to interact, develop relation, with multimedia basis.
\end{abstract}

Keywords: creative class; mediatek; multimedia; third place 


\section{PENDAHULUAN}

Menurut Yi Fu Tuan ruang dapat dideskripsikan sebagai lokasi yang tidak memiliki ikatan dengan manusia. Tidak ada nilai tambah karena hanya ruang terbuka yang mungkin dibatasi oleh tanda dan dipagari untuk menghalangi orang masuk. Ruang tidak mengundang atau memotivasi orang untuk bekerja kreatif di dalamnya. Bertentangan dengan ruang, tempat berarti bukan hanya sebuah lokasi dan dapat dideskripsikan sebagai ruang yang dibuat melalui pengalaman manusia. Cakupan lokasi pada konteks ini luas dan tidak terbatas. Tempat bisa berupa sebuah kota, wilayah, lingkungan, dan lainnya. Tempat dapat dikatakan merupakan ruang yang dibentuk oleh makna dan tujuan melalui pengalaman manusia. ${ }^{1}$

Menurut Ray Oldenburg pada struktur komunitas, manusia memiliki rumah sebagai tempat pertama dan tempat kerja sebagai tempat kedua. Ray Oldenburg juga merumuskan Third place yang disebut sebagai tempat meluangkan waktu di antara rumah dan tempat kerja yang bisa rutin dikunjungi di mana terjadi interaksi antar masyarakat untuk bertukar ide, berekreasi dan membangun relasi. Salah satu contoh Third place adalah perpustakaan sebagai tempat fisik, karena memenuhi aspek dan ciri-ciri Third place ${ }^{2}$. Perpustakaan dapat dipandang sebagai Third place karena memiliki kriteria seperti suasana ruang tanpa tertekan, suasana tanpa canggung karena perbedaan kedudukan sosial, interaktif dan suasana bersahabat. Selain itu perpustakaan memiliki tata ruang yang bertujuan mengakomodasi semua jenis orang dengan rasa nyaman. ${ }^{3}$

Namun demikian, perpustakaan yang semula diandalkan sebagai tempat mencari informasi dan ruang belajar saat ini ditinggalkan, khususnya oleh masyarakat kelas kreatif. Kebutuhan gaya hidup kelas kreatif yang dinamis tidak sesuai dengan suasana perpustakaan yang formal, dan aturan tegas bagi pengunjung serta waktu pelayanan yang singkat. Masyarakat kelas kreatif lebih akrab dengan penggunaan multimedia yang dilahirkan teknologi informasi dan komunikasi daripada pergi ke ruang koleksi media cetak dan ruang baca yang disediakan perpustakaan. Kelas Kreatif selain membutuhkan ruang fisik berisi informasi dalam bentuk media cetak dan tempat belajar, juga membutuhkan ruang fisik dengan fleksibilitas waktu pelayanan dan suasana santai berbasis multimedia untuk mencari dan menukar informasi, mengolah ide dan pikiran, dan berinteraksi.

Oleh karena itu untuk menjawab kebutuhan kelas kreatif, sebuah perpustakaan harus dikembangkan mengadaptasi gaya hidup masyarakat kelas kreatif yang akrab dengan multimedia. Arsitek-arsitek dunia telah mengembangkan perpustakaan multimedia yang dinamakan Mediatheque. Mediatheque bertujuan untuk menjadi lebih dari sekedar tempat mencari informasi untuk belajar dan ruang baca. Mediatheque menaungi ruang-ruang penyedia informasi dalam bentuk multimedia yang sesuai dengan perkembangan teknologi yang dipakai dan dibutuhkan oleh kelas kreatif. Mediatheque dapat mengakomodasi perilaku dan gaya hidup masyarakat khususnya kelas kreatif, yaitu dengan menyediakan ruang-ruang yang didukung oleh multimedia bersuasana non-formal untuk mencari informasi, mengolah ide dan pikiran, dan berinteraksi.

\section{Identifikasi Masalah}

Kelas Kreatif membutuhkan ruang fisik berisi informasi dalam bentuk media cetak dan tempat belajar, dengan fleksibilitas waktu pelayanan dan suasana santai berbasis multimedia untuk mencari dan menukar informasi, mengolah ide dan pikiran, dan berinteraksi. Namun demikian, ruang fisik yang dibutuhkan belum tersedia.

\footnotetext{
${ }^{1}$ Tuan, Y. (1977). Space and Place: the persepective of experience. University of Minnesota, Minneapolis.

2 Oldenburg, Ray. (1999). The great good place: Cafes, coffee shops, bookstores, bars, hair salons, and other hangouts at the heart of a community. New York: Marlowe

${ }^{3}$ Raquel Gonçalves Castro, "Library as a Third place”, diakses dari https://medium.com/@raquelgocastro/library-as-athird-place-e891dac6519f, pada tanggal 28 Januari 2020 pukul 15.00
} 
Mediatheque dapat menyediakan kebutuhan Kelas Kreatif berupa ruang fisik untuk mencari informasi, mengolah ide dan pikiran, dan berinteraksi, yang didukung oleh multimedia dengan suasana non-formal.

\section{Ruang Lingkup}

Materi Studi

Lingkup Spatial

Pembahasan dibatasi dalam lingkup kajian teoritis tentang arsitektur secara umum dan arsitektur kontemporer secara khusus. Permasalahan dalam bidang non-arsitektural dipaparkan untuk mempertajam dan melengkapi pembahasan utama.

\section{Lingkup Substansial}

Bagian-bagian objek studi yang akan diolah sebagai penekanan studi adalah elemen penataan pola tata ruang baik ruang dalam dan ruang luar yang mencakup aspek tampilan bangunan, prinsip penyusunan ruang, ekspresi ruang, bentuk ruang, elemen bidang dan pengisi ruang, organisasi dan hubungan ruang, pola sirkulasi ruang, skala dan proporsi ruang, serta warna dan tekstur ruang.

\section{Pendekatan}

Perencanaan dan perancangan perpustakaan menggunakan pendekatan Ekspresi Arsitektur Kontemporer.

\section{Rumusan Masalah}

Bagaimana wujud Mediatheque yang dirancang sebagai wadah komunitas masyarakat kelas kreatif untuk mencari dan bertukar informasi dalam bentuk multimedia, mengolah ide dan pikiran, berekreasi dan membangun relasi guna mendukung aktivitas Kelas Kreatif melalui pendekatan ekspresi arsitektur kontemporer?

\section{Tujuan}

a. Menyediakan sarana dan fasilitas untuk membaca, mengakses informasi multimedia dan pembelajaran bagi masyarakat kelas kreatif

b. Menyediakan tempat dengan suasana terbuka dan santai untuk berinteraksi, bertukar dan mengolah ide dan menyelenggarakan aktivitas yang berkaitan dengan edukasi

c. Meningkatkan wawasan dan pengetahuan masyarakat sehingga produktivitas dan kesejahteraan masyarakat kelas kreatif meningkat

\section{Sasaran}

Sasaran proyek utamanya adalah masyarakat kelas kreatif yang terdiri dari masyarakat yang menekuni bidang sains dan rekayasa, arsitektur dan desain, edukasi, seni musik dan hiburan dengan kebutuhan akan ruang untuk mengakses media informasi, mengolah ide dan pikiran, berekreasi dan membangun relasi.

\section{KAJIAN LITERATUR}

Third place adalah tempat apapun dalam hidup kita selain daripada tempat bekerja atau rumah. Tempat tersebut menjadi bagian dari pengalaman di tempat kerja yang tidak dapat ditawar. Mereka berperan penting untuk menarik dan menjaga motivasi kerja kreatif yang dibutuhkan untuk bersaing di masa depan. ${ }^{4}$

Third place dikembangkan di tengah masyarakat bukan karena ketidaksengajaan atau kebetulan, tetapi dirancang untuk menempatkan komunitas masyarakat pada posisi motivasi

\footnotetext{
${ }^{4}$ The Creation of Place Design Team White Papers, "Third places", diakses dari https://www.embracetheplace.com/wp-
} content/themes/EtP\%20Theme/docs/ 3thirdplaces.pdf, pada tanggal 28 Januari 2020 pukul 15.00 
bekerja yang dibutuhkan dalam konteks rekayasa sosial. Pengembangan Third place adalah sebuah proses bertahap, dan dirancang untuk meningkatkan pengalaman gaya hidup suatu komunitas, seperti makan, kehidupan malam, musik dan serta melatih kemampuan untuk mencari kesempatan, komunitas lingkungan dan lainnya.

Tanggung jawab atas pembangunan Third place juga memiliki beragam sisi. Kota atau daerah otoritas bertugas untuk menciptakan lingkungan dan infrastruktur, sedangkan perusahaan swasta menyediakan aktivitas dasar yang sebenarnya. Kelas kreatif harus mendapat pengakuan karena memiliki prioritas baru. Prioritas utama dari Third place adalah menyediakan lingkungan baru yang dapat dijadikan pilihan.

\section{METODE}

Pola Prosedural penulisan landasan konseptual ini menggunakan cara kerja penalaran deduktif dan komparasi objek studi. Terdapat 3 teknik pencarian data, yaitu:

\section{Studi Literatur}

Studi ini secara keseluruhan akan meliputi teori penekanan dan pendekatan arsitektur terkait, esensi objek studi, dan standar-standar tentang tipologi arsitektur terkait.

\section{Studi Lapangan Dan Wawancara}

Studi ini berupa pengamatan preseden yang sejenis dengan objek studi terkait. Pengamatan dilakukan dengan teknik pemotretan fisik dan deskripsi preseden. Selain itu, pencarian data juga diperoleh dari hasil wawancara kepada pihak-pihak yang terkait. Hasil wawancara berupa masukan isu-isu fungsional dan arsitektural yang terjadi secara aktual.

\section{Studi Komparasi}

Studi komparasi dengan cara melakukan perbandingan preseden terpilih. Komparasi ini memberi arahan kepada penulis untuk menentukan penekanan desain dan pendekatan arsitektural seperti apa nantinya. Suatu proses perancangan membutuhkan suatu metode yang memudahkan bagi perancang dalam mengembangkan ide rancangan. Metode yang digunakan dalam Mediatheque, lebih menekankan pada penjelasan secara deskriptif mengenai objek rancangan dan setiap permasalahan yang menjadi latar belakang perancangan. Jadi, tahapnya dimulai dari penjelasan secara deskriptif tentang fakta yang ada, kemudian dikembangkan melalui beberapa literatur yang menjadi standar dalam perancangan Mediatheque ini.

\section{Pencarian Ide Dan Gagasan}

Pada pencarian ide/gagasan dalam perancangan Mediatheque melalui beberapa tahapan sebagai berikut:

a. Pencarian ide/gagasan dengan menyesuaikan informasi tentang keadaan arsitektur nusantara yang berkembang di Kota Jakarta, khususnya dalam ruang lingkup pendidikan, serta seberapa besar peluang untuk memicu adanya kegiatan aktif dari kalangan akademisi, praktisi, komunitas maupun masyarakat dalam perkembangan perancangan, sehingga lahirlah satu gagasan untuk merencanakan fasilitas pendidikan berupa Mediatheque.

b. Pengembangan ide perancangan melalui penelusuran informasi dan data-data dari berbagai pustaka dan media yang kemudian ditinjau sebagai bahan perbandingan dalam pemecahan masalah.

\section{Penentuan Lokasi Perancangan}

Lokasi perancangan harus dapat mendukung fungsi bangunan, karena Mediatheque yang direncanakan di Kota Jakarta nantinya akan difungsikan sebagai bangunan komersial dan sebagai fasilitas dari pendidikan Kota Jakarta. Dalam perencanaan sarana dan prasarana Mediatheque perlu adanya syarat-syarat yang perlu diperhatikan untuk memenuhi tuntutan berfungsinya bangunan tersebut. Berikut ini merupakan kriteria lokasi yang perlu diperhatikan 
dalam penentuan lokasi perancangan:

a. Lokasi tapak sebaiknya berada di dekat pusat kota, terkait tempat yang mudah dicapai, sehingga diharapkan lebih mudah menarik pengunjung.

b. Lokasi tapak sebaiknya strategis dengan memperhatikan fungsi bangunan-bangunan lain di sekitarnya yang dapat menunjang peran aktif fasilitas-fasilitas dalam rencana rancangan.

c. Fasilitas perpustakaan membutuhkan ketenangan untuk memenuhi kenyamanan aktivitas di dalamnya. Dengan demikian, meskipun tapak berada di dekat pusat kota, harus dipertimbangkan pula batas-batas yang melingkupi tapak.

\section{Pengumpulan Data}

Pengumpulan data sangat diperlukan dalam perancangan, karena dalam tahap ini dijelaskan mengenai deskripsi obyek perancangan serta beberapa literatur yang dijadikan sebagai standar dalam perancangannya. Pengumpulan data dilakukan untuk memperoleh standar dari beberapa sumber atau literatur, serta dokumentasi dari survey yang telah dilakukan. Data-data yang diperoleh tersebut kemudian diolah dan dikaji kesesuaiannya dengan perancangan pusat Mediatheque.

Metode yang digunakan dalam pengumpulan data dibagi ke dalam dua kategori, yaitu data primer dan data sekunder. Data primer yaitu data yang diperoleh langsung dari sumbernya, diamati dan dicatat. Data sekunder yaitu data yang tidak diperoleh sendiri, melainkan data yang diperoleh dari bahan perpustakaan. Berikut dapat dijelaskan secara rinci terkait pengumpulan data secara primer dan sekunder:

\section{Data Primer}

Data tapak adalah data primer yang diperoleh melalui proses pengambilan data secara langsung pada lokasi. Pengumpulan data yang dilakukan adalah survei lapangan secara langsung pada lokasi untuk mendapatkan data yang diperlukan dalam proses perancangan. Data-data yang diperoleh kemudian digunakan sebagai bahan kajian yang lebih lanjut dalam perancangan Mediatheque. Pada data tapak, beberapa data yang diperlukan serta metode yang dilakukan dalam perolehan data tersebut dijelaskan sebagai berikut:

a. Data RDTRK dan RTRW. Data ini dibutuhkan untuk mengetahui data terkait peraturan yang ditetapkan pemerintah dalam pembangunan, seperti terkait peruntukan lahan dan peraturan mengenai pendirian bangunan (IMB), Koefisien Dasar Bangunan (KDB), Koefisien Luas Bangunan (KLB), dan Garis Sempadan Bangunan (GSB), dengan demikian, bangunan yang dirancang nantinya akan sesuai dengan ketentuan umum pembangunan yang ditetapkan oleh Peraturan Daerah.

Metode yang digunakan dalam pengumpulan data tersebut adalah dengan datang langsung kepada instansi terkait untuk mengajukan permohonan pengambilan data yang dibutuhkan tersebut.

b. Data kondisi eksisting lapangan. Data tersebut meliputi data batas tapak, data kondisi di sekitar tapak, kondisi fisik alamiah tapak, sirkulasi pada tapak.

Dalam merancang Mediatheque, metode membangun yang digunakan dalam proyek ini adalah dengan metode infill. Metode infill adalah usaha menyisipkan satu bangunan pada lahan kosong dalam satu lingkungan yang memiliki karakteristik kuat. Sedangkan untuk desainnya, penulis memilih metode contrast. Bangunan proyek beradaptasi dengan bangunan sekitar tetapi tetap memiliki keunikan dan bisa mempresentasikan dirinya. Adaptasi yang tercipta akan membuat keserasian sehingga lanskap yang tercipta tidak timpang.

\section{Data Sekunder}

Data sekunder adalah data atau informasi yang tidak berkaitan langsung dengan obyek perancangan tetapi mendukung proses menyusun program dalam perancangan yaitu pengumpulan data dari literatur atau referensi tentang bangunan Mediatheque, meliputi: 
a. Referensi terkait definisi dan teori bangunan secara umum dan lebih khusus mengenai Mediatheque

b. Referensi terkait dengan program utama, program pendukung dan fasilitas yang diperlukan pada Mediatheque serta pola dan tatanan ruang yang digunakan dalam bangunan

c. Referensi terkait standar ruangan yang dipakai dalam Mediatheque. Standar ini digunakan sebagai acuan dalam menentukan luasan ruang yang dirancang.

Data-data literatur tersebut akan digunakan sebagai standar yang dipakai dalam tahap analisa fungsi, aktivitas, pengguna, dan analisis ruang.

\section{DISKUSI DAN HASIL}

Di dunia Arsitektur diciptakan terobosan konsep perpustakaan modern yang disebut Mediatheque. Mediatheque atau Multimedia library adalah lembaga publik yang berfungsi sebagai perpustakaan, tidak hanya berisi media cetak dan buku elektronik, surat kabar dan majalah, tetapi juga materi multimedia seperti video dan rekaman suara.

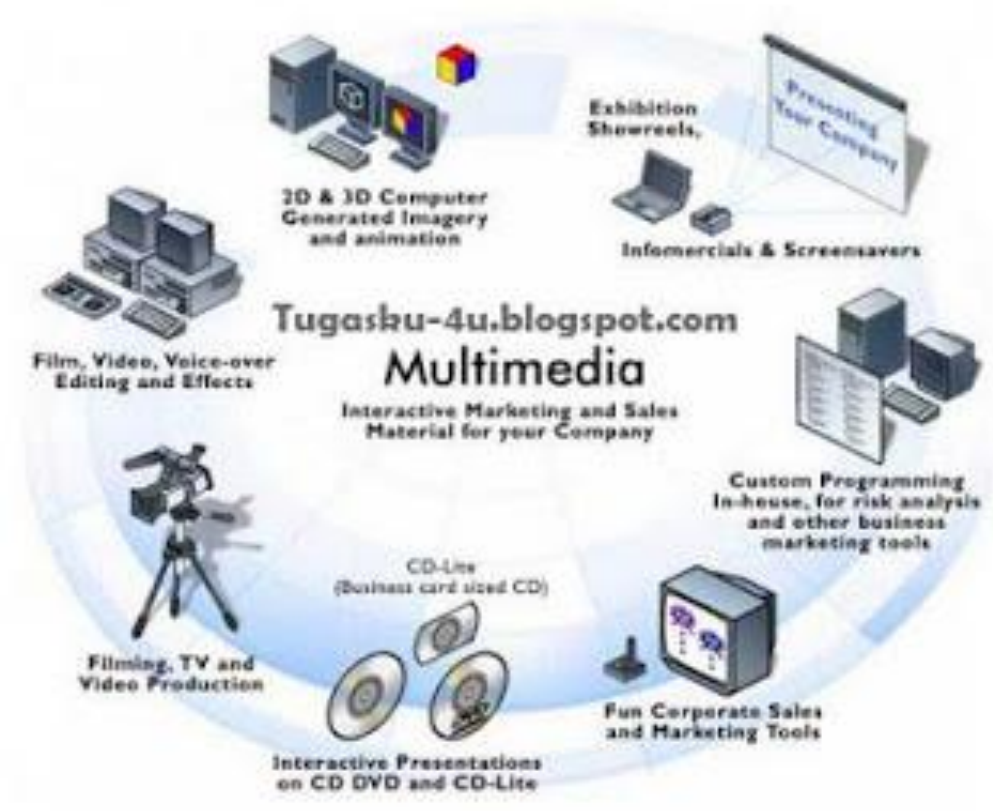

Gambar 1. Jenis-jenis Multimedia

Sumber: http://alfjrshare.blogspot.com/2014/02/pengertian-dan-macam-macam-multimedia

Multimedia adalah penggunaan dan pemrosesan beberapa media (teks, audio, grafis, animasi, video, and interactivity) yang berbeda untuk menyampaikan informasi. Dalam kategori ini media yang digunakan adalah: Media Teks, Media Audio, Media Video, Media Animasi, Media Graph/Image, Media Interactivity, Media Special Effect, dsb. Penggunaan Multimedia dalam menyampaikan informasi adalah ciri Mediatheque sebagai bentuk modernisasi dari perpustakaan yang sudah ada. Mediatheque menjadi sebuah wadah pengetahuan yang tidak hanya menyajikan media terbatas buku. Di samping itu juga terdapat pelayanan informasi, kafe, ruang audio, ruang baca santai, ruang galeri, ruang pertunjukkan film dan ruang baca atau kerja individu maupun kelompok. 


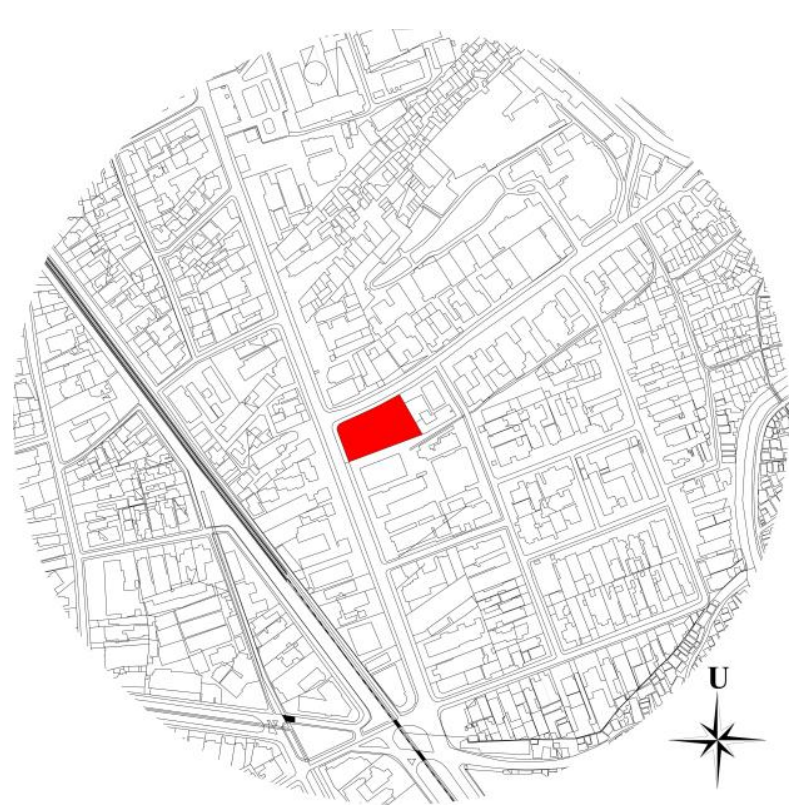

Gambar 2. Peta LRK Autocad Tapak

Sumber: Penulis, 2019

Tapak berada pada Jl. Cikini Raya, Cikini, Menteng, Jakarta Pusat, mempunyai luas tapak $4.100 \mathrm{~m}^{2}$ dengan batas wilayah sebagai berikut:

- Sebelah Utara: Jl. Raden Saleh Raya

- Sebelah Timur: Gedung toko

- Sebelah Selatan: Gedung Kantor

- Sebelah Barat: Jl. Cikini Raya

Letak tapak menurut peta lembar rancang kota zonasi DKI Jakarta dikategorikan sebagai zona pemerintahan.

Tabel 1. Tabel Intensitas Ruang

\begin{tabular}{c|c|c|c|c|c|c}
\hline KDB & KLB & KB & KDH & KTB & TIPE & PSL \\
\hline 55 & 2.4 & 8 & 30 & 55 & T & P \\
\hline \multicolumn{7}{c}{ Sumber: LRK Jakarta 2019 }
\end{tabular}

Konsep Mediatheque ini akan digunakan dalam perancangan suatu Media Center atau Media Library untuk menanggapi fenomena-fenomena yang terjadi di Kota Jakarta. Pembangunan Mediatheque direncanakan terletak di kawasan Cikini dekat dengan bangunanbangunan sekolah, institusi pendidikan, stasiun kereta api, dan lain lain. Mediatheque mengintegrasikan ilmu perpustakaan dengan seni dan budaya, berbasis multimedia. Mediatheque terlahir karena perkembangan infomasi yang semakin pesat dan berkurangnya tempat komunal untuk masyarakat sehingga bisa dikatakan bahwa Mediatheque merupakan sebuah konsep modern dalam dunia perpustakaan. Berbeda dengan Perpustakaan, pada Mediatheque tidak hanya penulis dan peneliti saja yang dapat menyebarluaskan/ mendistribusikan karya mereka, namun seniman dan budayawan juga dapat menyebarluaskan/ mendistribusikan ide, kreatifitas, dan karya mereka. Hal tersebut menyebabkan masyarakat semakin banyak dan mudah menerima informasi dan pengetahuan melalui berbagai macam media ${ }^{5}$.

\footnotetext{
${ }^{5}$ Eka Hermawan, Aditya. 2009. “Perpustakaan Hybrid di Yogyakarta”. Skripsi. Jurusan Arsitektur. Fakultas Teknik. Universitas Atma Jaya Yogyakarta
} 
Perkembangan teknologi mengubah cara masyarakat khususnya kelas kreatif dalam mendapatkan maupun bertukar informasi. Dunia digital diandalkan karena kemudahan mengakses jumlah data dan informasi yang besar dengan cepat. Namun banyaknya data yang dihimpun di dunia digital tidak semuanya lengkap dan otentik, padahal dunia digital juga diandalkan sebagai sarana belajar ${ }^{6}$.

Perkembangan teknologi yang memungkinkan penyebaran data, pertukaran informasi dan penyajian informasi dalam jumlah besar dan dapat diakses secara cepat mendorong perubahan perilaku masyarakat dari mencari informasi dalam bentuk fisik media cetak ke informasi digital yang diakses melalui alat elektronik. Namun diketahui bahwa informasi yang diperoleh dari internet kadangkala tidak penuh, sedangkan informasi yang didapatkan dari perpustakaan bisa secara lengkap beserta dokumen fisiknya.

Peran perpustakaan sebagai sumber informasi semakin terabaikan, sedangkan di saat yang sama minat masyarakat terhadap informasi tinggi. Perkembangan teknologi komunikasi dan informasi yang begitu cepat mempengaruhi eksistensi perpustakaan. Saat ini perpustakaan sebagai tempat pengumpulan dan penyaji informasi menjadi kurang popular seiring waktu karena kemudahan mengakses informasi di dunia digital melalui multimedia.

\section{Hasil Perancangan}

Bangunan Mediatheque dirancang berdasarkan dengan konsep yang didukung oleh analisa. Untuk merancang bangunan Mediatheque ini dilakukan pengelompokkan jenis kegiatan atau zoning yaitu; pengunjung, pengelola dan servis. Untuk mengatur penempatan kelompok kegiatan dibagi menurut arah orientasi jalan. Zoning pengunjung diatur menghadap jalan Cikini Raya di barat, zonasi pengelola menghadap bangunan di timur dan zonasi servis menghadap Jalan Raden Saleh di utara.
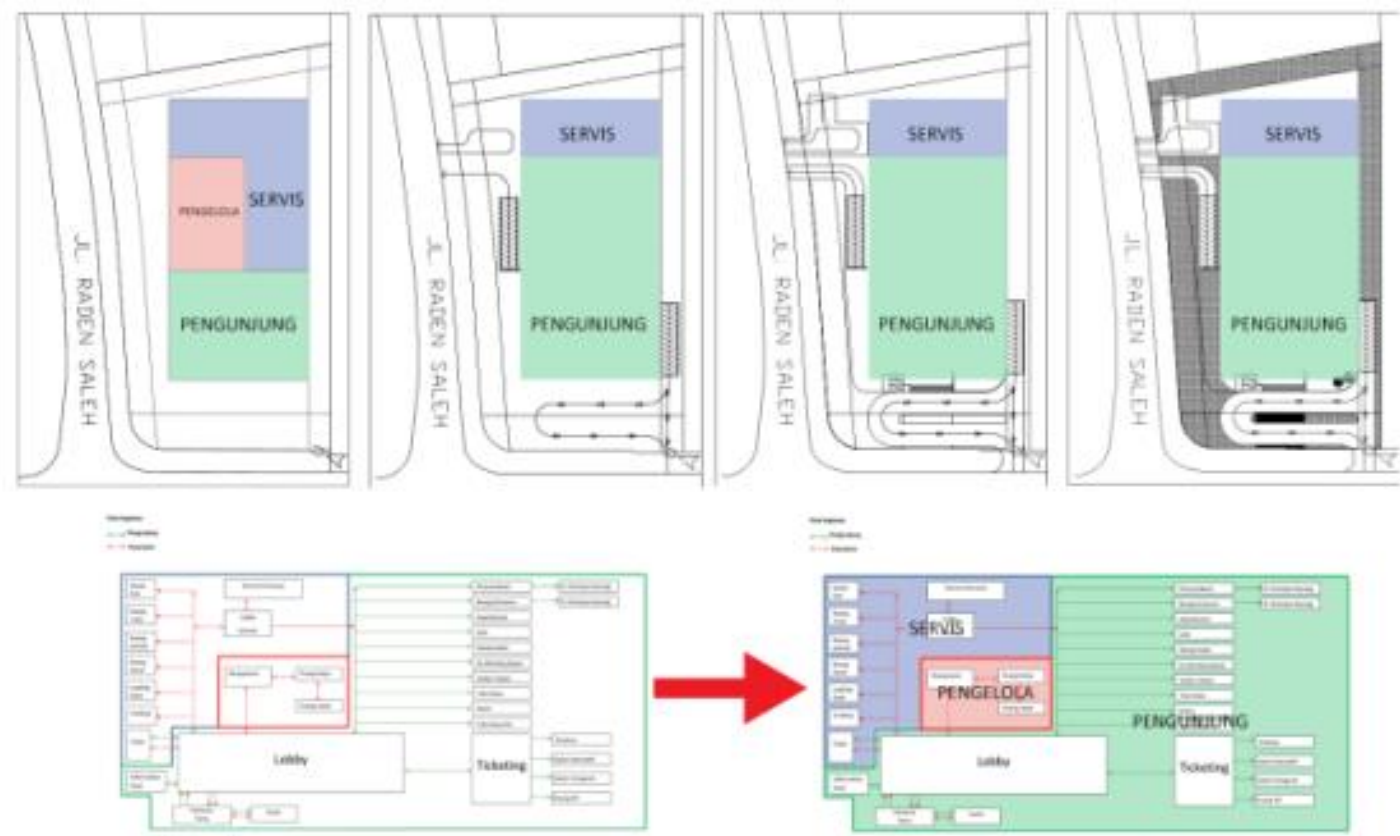

Gambar 3. Gambar Zoning

Sumber: Penulis, 2019

\footnotetext{
6 Puspitasari, Erindha. 2010. "Perpustakaan di Yogyakarta Dengan Penerapan Arsitektur Modern”. Skripsi. Jurusan Arsitektur. Fakultas Teknik. Universitas Sebelas Maret Surakarta
} 

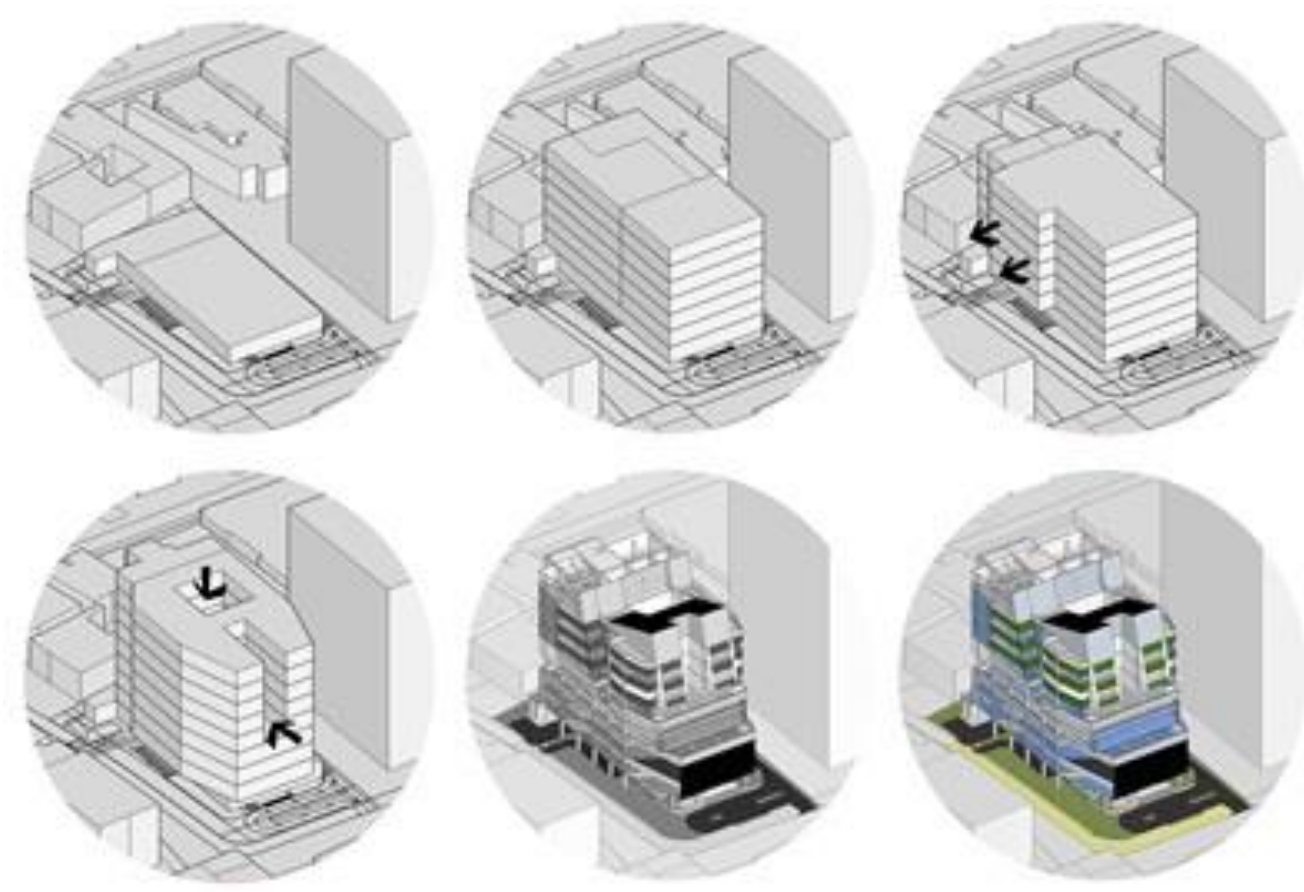

Gambar 4. Design Scheme

Sumber: Penulis, 2019

Konsep perancangan bangunan mengadaptasi unsur aksesibilitas dari ciri-ciri Third place. Unsur aksesibilitas sejalan dengan teori permeability. Pada teori permeability terdiri dari unsur aksesibilitas dan visibilitas. Unsur tersebut menjunjung penciptaan ruang secara fisik yang dinamis dan terbuka ${ }^{7}$. Keterbukaan menjadi ciri-ciri dari arsitektur tropis sehingga pendekatan desain arsitektur tropis diterapkan pada perancangan bangunan ini.

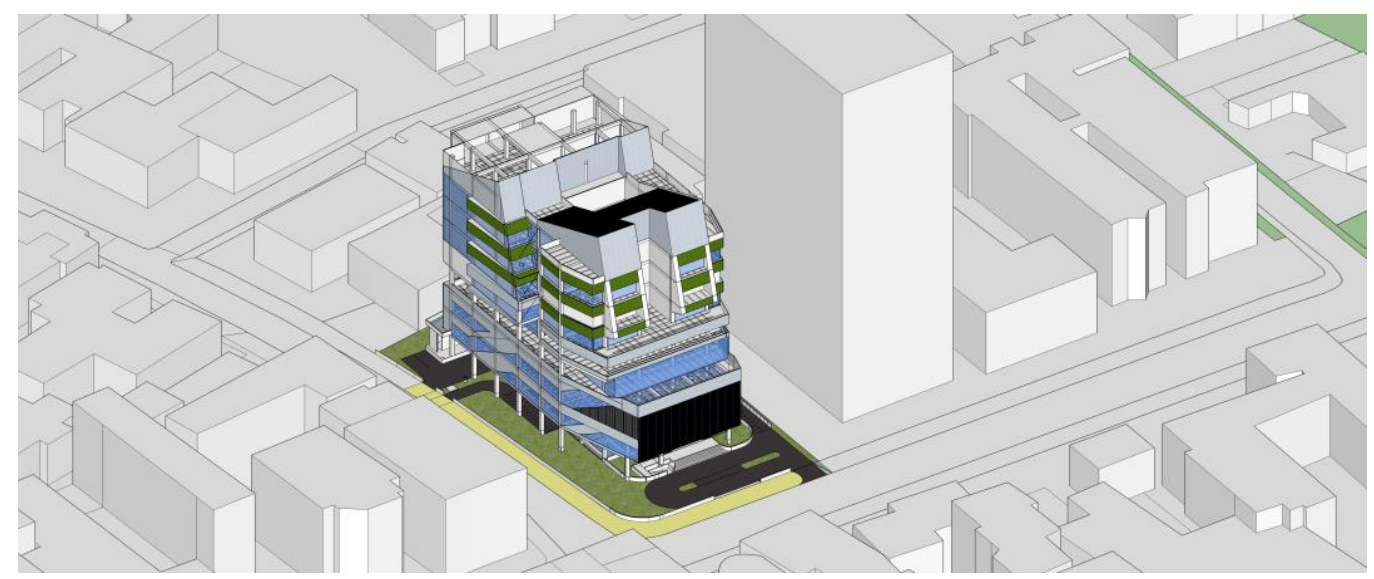

Gambar 5. Gubahan Massa

Sumber: Penulis, 2019

Design scheme berawal dari gubahan massa yang dikelompokkan atas area pengunjung, area servis dan area pengelola yang mana diposisikan sesuai arah orientasi matahari dan jalan. Pada proses pembentukan gubahan massa ini diberikan bukaan pada atap dan fasad agar pencahayaan alami dari iklim tropis dapat dimanfaatkan untuk kegiatan pengunjung bangunan.

\footnotetext{
${ }^{7}$ Department of Architecture The Chinese University of Hong Kong. (2006). Architecture of Permeability - Urban Redevelopment of
} Fa Yuen Street. Hong Kong: Lau Man Kuen Ephes 


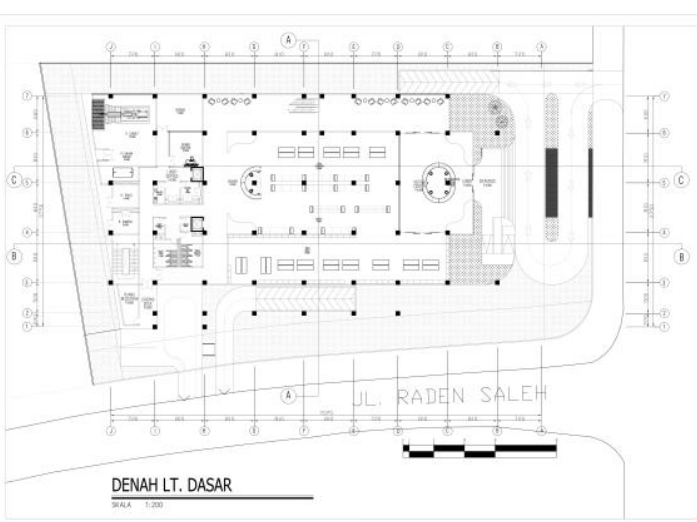

Gambar 6. Denah Lantai Dasar

Sumber: Penulis, 2019

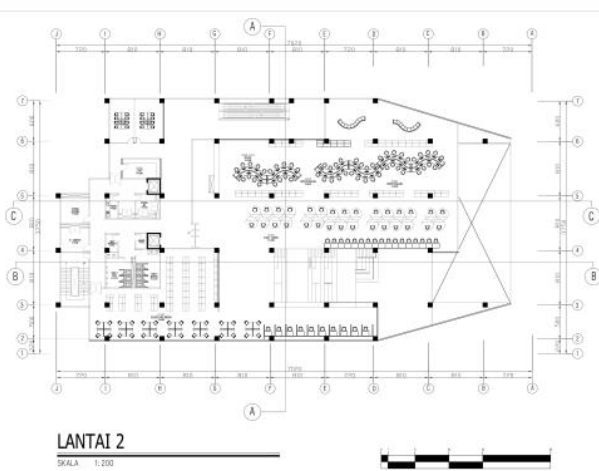

Gambar 8. Denah Lantai 2

Sumber: Penulis, 2019

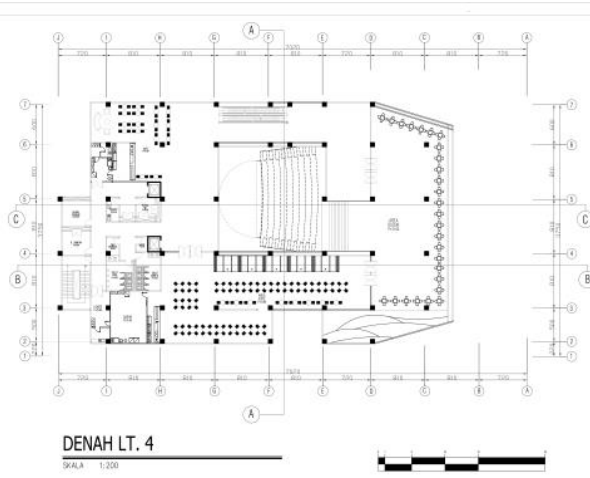

Gambar 10. Denah Lantai 4 Sumber: Penulis, 2019

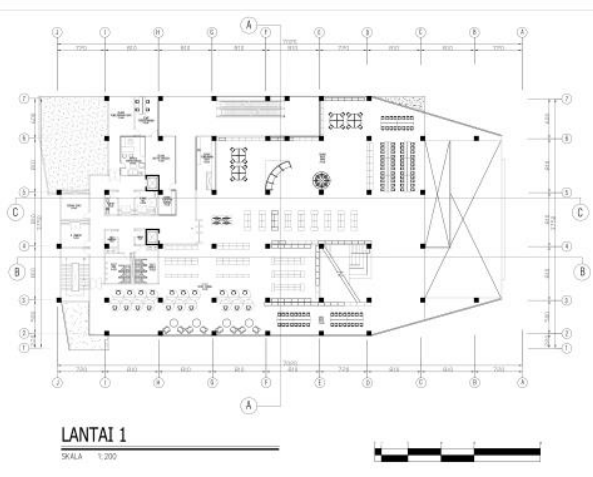

Gambar 7. Denah Lantai 1 Sumber: Penulis, 2019

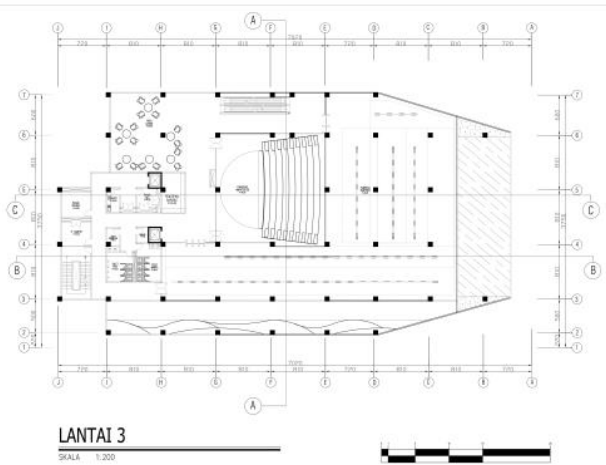

Gambar 9. Denah Lantai 3 Sumber: Penulis, 2019

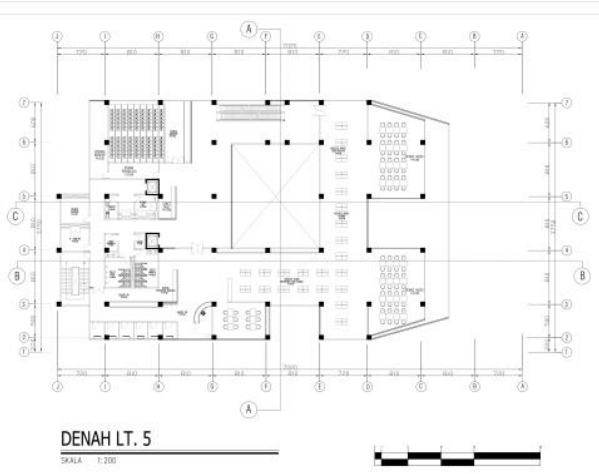

Gambar 11. Denah Lantai 5 Sumber: Penulis, 2019 


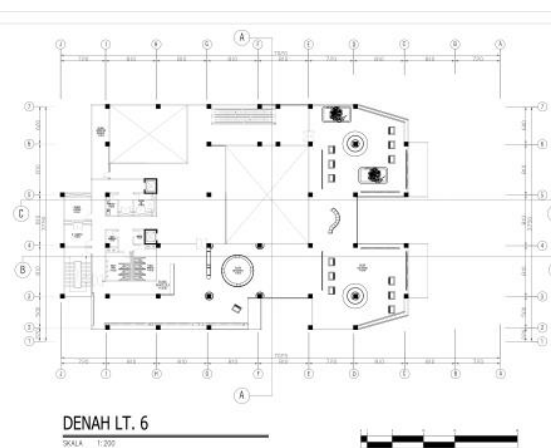

Gambar 12. Denah Lantai 6 Sumber: Penulis, 2019

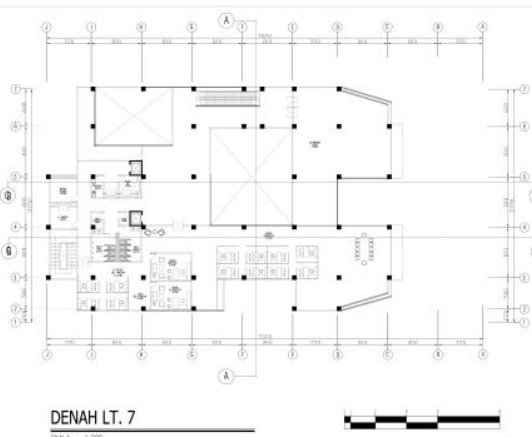

Gambar 13. Denah Lantai 7 Sumber: Penulis, 2019

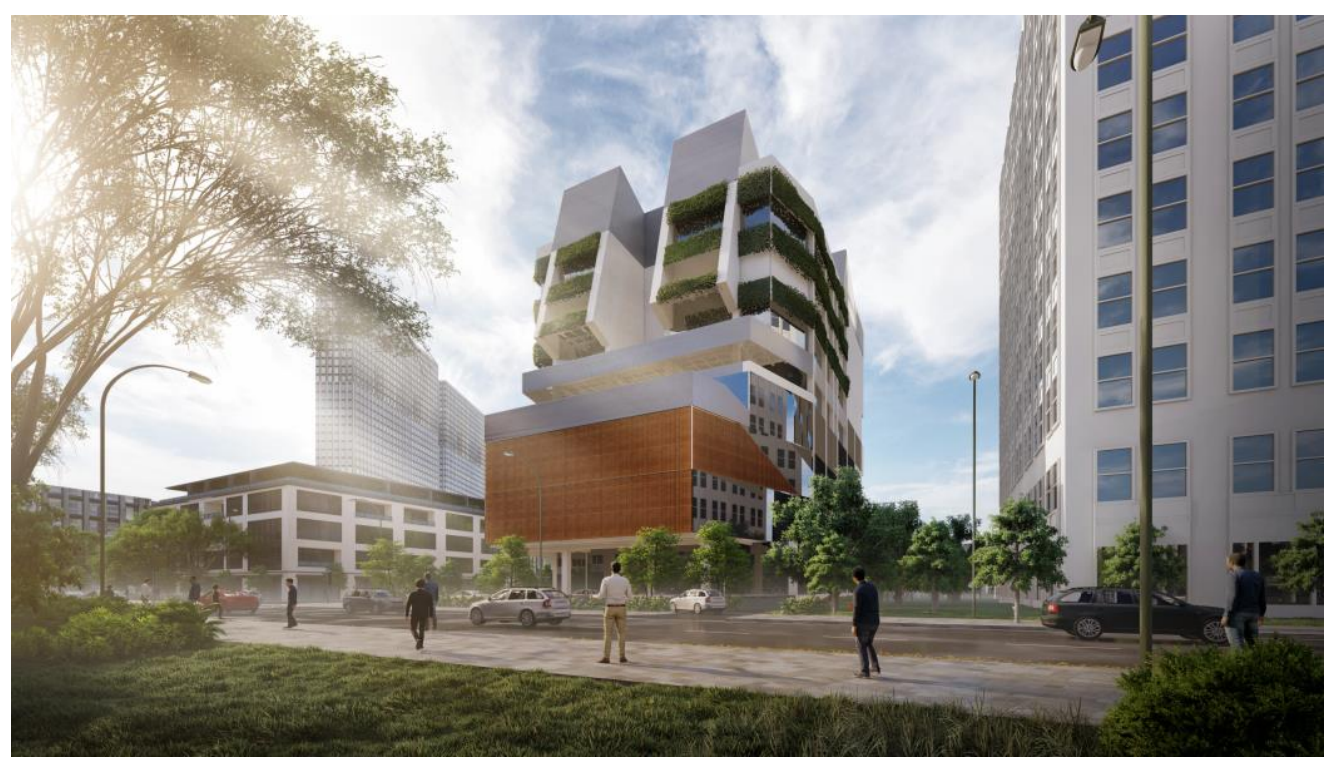

Gambar 14. 3D Eksterior

Sumber: Penulis, 2019

Fasad bangunan terdiri dari sekat masif berupa dinding dan sekat transparan berupa kaca untuk memanfaatkan cahaya alami dan meningkatkan visibilitas bangunan. Selain itu penggunaan teritis untuk menghalangi sinar matahari berlebih dan vertical garden diaplikasikan untuk menyerap hawa panas.

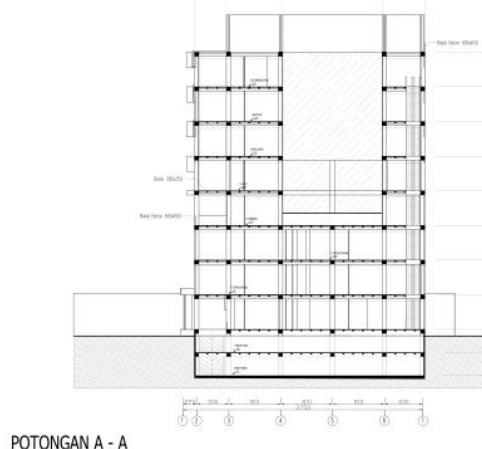

Gambar 15. Potongan

Sumber: Penulis, 2019 


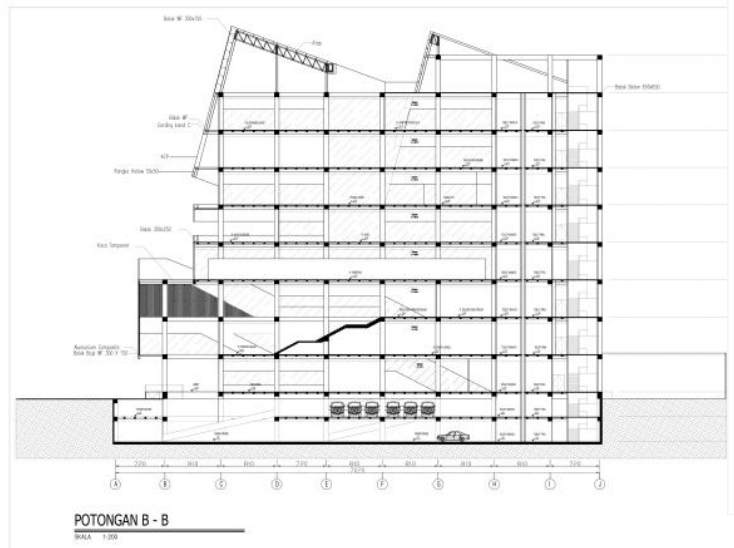

Gambar 16. Potongan

Sumber: Penulis, 2019

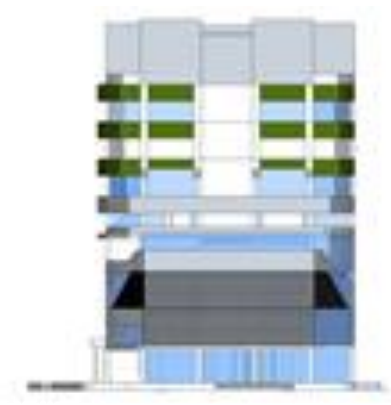

Gambar 18. Tampak Depan

Sumber: Penulis, 2019

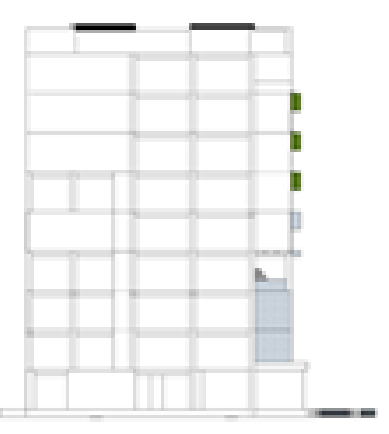

Gambar 20. Tampak Belakang Sumber: Penulis, 2019

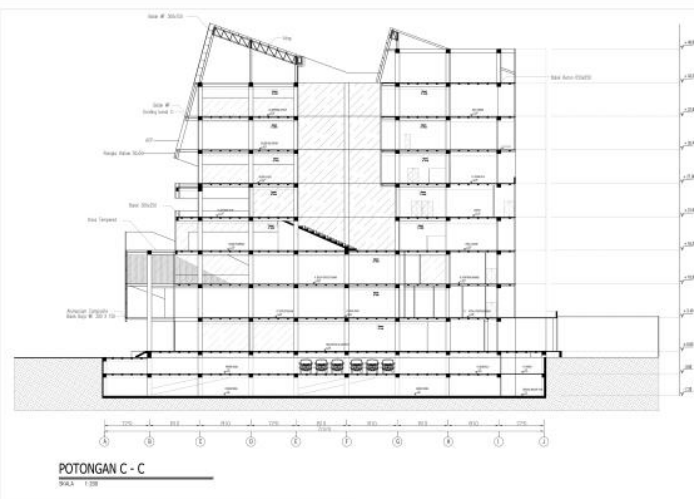

Gambar 17. Potongan

Sumber: Penulis, 2019

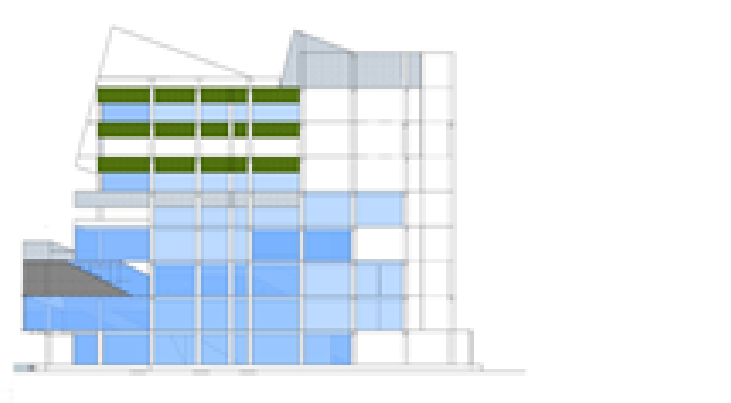

Gambar 19. Tampak Samping Kanan

Sumber: Penulis, 2019

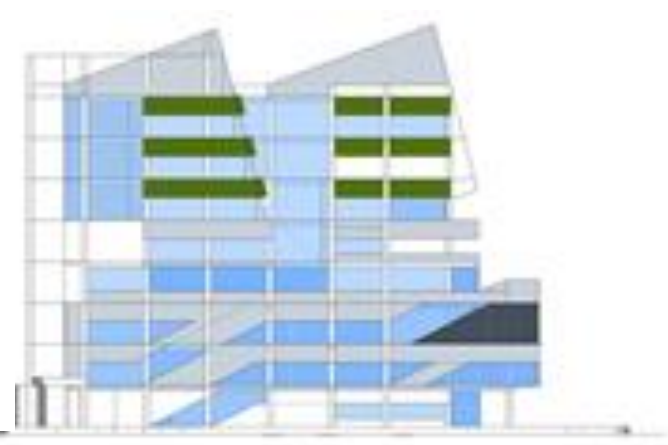

Gambar 21. Tampak Samping Kiri

Sumber: Penulis, 2019

\section{Program Dan Kegiatan}

Perhitungan kebutuhan ruang dari setiap program dimaksudkan untuk mendapatkan besaran luas masing-masing ruang melalui standard. Acuan yang digunakan pada perancangan ruang dari bangunan Mediatheque di Cikini, yaitu:

a. Architect's Data, 1 \& 2, Ernst Neufert, John Wiley and Sons, New York, 1980

b. Time Saver Standards for Building Type, Joseph de Chiarra, Mcgraw-Hill, 1986 
Berikut nama ruang berdasarkan program yang terdapat di Mediatheque di Cikini, yaitu:

Tabel 2. Program dan Kegiatan

\begin{tabular}{|c|c|c|}
\hline Kelompok Kegiatan & Sub Kelompok Kegiatan & Pelaku Kegiatan \\
\hline \multirow{7}{*}{ Fungsi Utama } & Perpustakaan & \multirow{7}{*}{$\begin{array}{l}\text { Pengunjung } \\
\text { Pengelola }\end{array}$} \\
\hline & Ruang Pameran & \\
\hline & Ruang Audio & \\
\hline & Bioskop & \\
\hline & Galeri Hologram & \\
\hline & Galeri Interaktif & \\
\hline & Ruang VR & \\
\hline \multirow{6}{*}{ Fungsi Publik } & Amfiteater & \multirow{6}{*}{$\begin{array}{l}\text { Pengunjung } \\
\text { Pengelola }\end{array}$} \\
\hline & Visitor Center & \\
\hline & Toko Buku & \\
\hline & Distro \& Souvenir shop & \\
\hline & Co-working space & \\
\hline & Kafe & \\
\hline Kegiatan Penunjang & Kantor & Pengelola \\
\hline
\end{tabular}

Sumber: Penulis, 2019

\section{KESIMPULAN DAN SARAN}

Ruang ketiga (Third place) selalu dibutuhkan oleh masyarakat. Di ruang ketiga masyarakat bisa menggunakan waktu untuk bersosialisasi dan bebas berinteraksi. Selain itu, ruang ketiga dibutuhkan oleh masyarakat untuk bertukar ide, memperoleh informasi dan berbagi informasi melalui perantara alat teknologi. Ruang ketiga juga bermanfaat untuk meningkatkan taraf hidup manusia dan memperbaiki kesenjangan interaksi dengan mewadahi aktivitas dan kegiatan komunitas masyarakat. Oleh karena itu, ruang ketiga bermanfaat bagi komunitas masyarakat.

Contoh ruang ketiga adalah tempat penyedia informasi yaitu perpustakaan. Perpustakaan menjadi tempat untuk mencari informasi dan belajar. Semua lapisan masyarakat dan apapun profesinya bisa berkunjung dan mengambil manfaat dari keberadaan perpustakaan. Perpustakaan juga merupakan tempat pendidikan informal yang mendukung kegiatan pembelajaran bagi pengunjungnya, karena menyediakan sumber informasi. Dengan demikian, orang yang berkunjung dapat mencari ilmu untuk mengembangkan wawasan dan potensi dirinya.

Saat ini, informasi dan pengetahuan sangat dibutuhkan oleh semua kalangan dan perpustakaan dapat menyediakan kebutuhan tersebut. Namun demikian, perpustakaan telah mulai ditinggalkan oleh masyarakat, khususnya oleh kelas kreatif, karena kegiatan mencari buku di perpustakaan dianggap tidak praktis. Kelas kreatif adalah generasi masa kini, karena sering menggunakan teknologi terkini dan mengakses informasi dalam bentuk digital. Teknologi saat ini memudahkan akses informasi secara cepat dan banyak dalam waktu singkat. Selain itu adanya gawai memudahkan aktivitas mencari informasi untuk pengetahuan maupun belajar.

Namun demikian, informasi di internet tidak semua benar, sehingga dibutuhkan tempat yang dapat menjadi sumber informasi lengkap berupa multimedia dan ruang belajar bagi masyarakat. Sebuah wadah sumber informasi multimedia dan ruang belajar yang mendukung proses kreatif adalah Mediatheque. Mediatheque dikembangkan dari perpustakaan. Mediatheque dipilih untuk menjawab kebutuhan ruang ketiga di tengah masyarakat sekaligus kebutuhan bagi komunitas kelas kreatif khususnya di kawasan Cikini. 
Untuk mendukung kegiatan di dalam Mediatek pendekatan arsitektur yang dipilih adalah arsitektur tropis. Berdasarkan teori third place, pendekatan arsitektur memiliki unsur aksesibilitas dan visibilitas yang serupa dengan teori permeabilitas bangunan. Pada massa bangunan, bangunan dibuat bukaan di tengah massa untuk memasukkan sinar matahari sebagai pencahayaan alami bangunan. Namun untuk menyaring sinar matahari berlebih, pada fasad dibuat teritis dan dipasang kisi-kisi. Selain itu, vertical garden juga dibuat agar suhu dalam bangunan tetap nyaman.

\section{REFERENSI}

Badan Pusat Statistik, Provinsi DKI Jakarta dalam Angka. Jakarta, 2018

Badan Pusat Statistik, Kota Administrasi Jakarta Pusat dalam Angka. Jakarta, 2018

Badan Pusat Statistik, Kecamatan Menteng dalam Angka. Jakarta, 2018

Basuki, S. (1991). Pengantar Ilmu Perpustakaan. Jakarta: Gramedia Utama

Department of Architecture The Chinese University of Hong Kong. (2006). Architecture of

Permeability - Urban Redevelopment of Fa Yuen Street. Hong Kong: Lau Man Kuen Ephes

Eka H., A. (2009). "Perpustakaan Hybrid di Yogyakarta”. Skripsi. Jurusan Arsitektur. Fakultas

Teknik. Universitas Atma Jaya Yogyakarta

Erickson, T.J. (2012). The Millenials. RSA Journal vol. 158, No. 5550

Oldenberg, R. (1999). The Great Good Place. Da Capo Press

Puspitasari, E. (2010). "Perpustakaan di Yogyakarta Dengan Penerapan Arsitektur Modern".

Skripsi. Jurusan Arsitektur. Fakultas Teknik. Universitas Sebelas Maret Surakarta

Tuan, Y. (1977). Space and Place: the persepective of experience. University of Minnesota,

Minneapolis

https://www.brookings.edu/blog/up-front/2016/09/14/third-places-as-community-builders/

www.embracetheplace.com/wp-content/themes/EtP\%20Theme/docs/3thirdplaces.pdf

diakses 24 Juli 2019

https://medium.com/launchcapital/the-welcome-resurgence-of-third-places-5149b97eec82

https://medium.com/@raquelgocastro/library-as-a-third-place-e891dac6519f 